\title{
Emotion Recognition and Aging: Research Perspectives
}

Lapo Pierguidi and Stefania Righi*

Department of Neuroscience, Psychology, Drug Research and Child's Health, University of Florence, Italy

*Corresponding author: Stefania Righi, Department of Neuroscience, Psychology, Drug Research and Child's Health, University of Florence, Italy, Tel: +23408037208680; E-mail: wilson.onuigbo@gmail.com

Received date: June 01, 2016; Accepted date: June 02, 2016; Published date: June 09, 2016

Copyright: @ 2016 Pierguidi L, et al. This is an open-access article distributed under the terms of the Creative Commons Attribution License, which permits unrestricted use, distribution and reproduction in any medium, provided the original author and source are credited.

\section{Editorial}

An important aspect that has raised the interest of many scholars in last decades concerns the changes in conscious and unconscious perception that occurs over the life span. In particular, social perception has gained great consideration due to his fundamental role in the human interaction dynamics. The capacity of forming impressions and make inferences about other people refers broadly to the ability to understand and react appropriately to the social signals sent out by other people. This ability in identify the other people's emotions is a predictor of well-being, mental health and social competency.

The recognition of other people's feelings is possible through the decoding of different kinds of expression such as changes in facial expression, eye contact, body posture and movements. A difficulty in emotion recognition, that is a central component of nonverbal communication, is considered a critical factor associated with the maintenance of various psychopathologies [1]. One of the main clues that people grasp to identify emotional states of others is linked to changes in facial expression. There are in fact a wide range of neural systems that are involved in this capacity including: dorsolateral prefrontal cortex [2], ventral striatum [3], superior temporal sulcus $[4,5]$ and processing areas in the parietal and occipital lobes [6]. The amygdala is specialized in the detection of facial expressions of fear [6,7-11] whereas basal ganglia and insula are specialized in the detection of disgusted faces [3]. Several studies point out that older adults have more difficulty than younger when recognizing emotion from facial expressions, in particular for anger, sadness and fear $[12,13]$. Although there are many experimental studies that have focused on this aspect, the link between the impairment in other's emotions recognition and the cognitive modifications that occur during life span is still debated. Some scholars have pointed out a correlation between age-related changes in the capacity of emotion recognition and the well-known modifications of brain regions caused by aging $[3,14,15]$. Specifically, the age-related modifications of frontal and temporal areas may have a main role in emotion recognition impairments. [16,17]. Moreover some studies indicated also a reduction of the volume of amygdala with age [18-21]. Following this evidences we might hypothesize that the deficit in the recognition of some emotional expressions by older people could depend on the loss of brain volume due to aging neural modifications in some areas relevant for emotion recognition $[9,17,23]$. On the other hand, some scholars hypothesized a further theory that suggests the establishment of a perceptual bias in elderly people, known as the "Positivity effect". This effect would be the reflection of an information processing bias in attention and memory that impairs the capacity of pay attention on negative emotional stimuli when presented jointly to positive ones [24-26]. The "Positivity effect" is evident only when positive information (e.g. happy faces) and negative information (e.g. angry, disgusted and sad faces) are presented in pairs. Differently, when the negative stimuli are shown individually, the opposite pattern has been observed in older people which exhibit longer fixation times on negative pictures compared to positive ones [26,27]. How positivity bias affects the recognition of the principal emotional expressions is still under debate. Williams et al. [28] hypothesized that the positivity bias might be linked to age changes in motivational priorities. This could result in a perceptional bias in the classification of negative and positive emotions. Furthermore this effect may lead to the modification of the perception of social aspects in elderly people due to their more extensive life experience in analyzing emotional cues and interpersonal communication that could determine changes in attentional allocation processes. Another idea that could explain the positivity effect suggested that elderly people may use different facial exploration patterns. Sullivan [27] experimentally showed that in elderly subjects there is a preferential exploration of the mouth area when emotional faces are presented. This behavior contrasts with the young people facial exploration strategy that show a preference in the exploration of the eye region (that is more informative in the classification of emotional faces). It is therefore possible that the older people use different decoding strategies of emotional expressions, as they rely on different areas of the face than younger people. If this was confirmed, then we could hypothesize that the elderly people difficulties in labeling negative emotional faces is linked to a differentiation in the face exploration patterns. These differences could result in impairments in emotional faces perception and especially could affect the categorization of these stimuli. In the light of these evidences, it is clear that older adults are worse than younger adults on at least some emotions, with a clear general trend for the worsening of emotion recognition with age. Although, the presented literature have provided interesting insights, a full explanation for this phenomenon has yet to be established. This indicates the need for further studies that explore emotional face processing and categorization during the life cycle.

\section{References}

1. Surcinelli P, Codispoti M, Montebarocci O, Rossi N, Baldaro B (2006) Facial emotion recognition in trait anxiety. J Anxiety Disord 20: 110-117.

2. Sprengelmeyer R, Rausch M, Eysel UT, Przuntek H (1998) Neural structures associated with recognition of facial expressions of basic emotions. P Roy Soc Edinb B 265: 1927-1931.

3. Calder AJ, Keane J, Manly T, Sprengelmeyer R, Scott S, et al. (2003) Facial expression recognition across the adult life span. Neuropsychologia 41: 195-202.

4. Narumoto J, Okada T, Sadato N, Fukui K, Yonekura Y (2001) Attention to emotion modulates fMRI activity in human right superior temporal sulcus. Cognitive Brain Res 12: 225-231.

5. Winston JS, O'Doherty J, Dolan RJ (2003) Common and distinct neural responses during direct and incidental processing of multiple facial emotions. Neuroimage 20: 84-97. 
Citation: Pierguidi L, Righi S (2016) Emotion Recognition and Aging: Research Perspectives. Clin Exp Psychol 2: e106. doi:

Page 2 of 2

6. Posamentier MT, Abdi H (2003) Processing faces and facial expressions. Neuropsychol Rev 13: 113-143.

7. Whalen PJ, Shin LM, McInerney SC, Fischer H, Wright CI, et al. (2001) A functional MRI study of human amygdala responses to facial expressions of fear versus anger. Emotion 1: 70.

8. Phan KL, Wager T, Taylor SF, Liberzon I (2002) Functional neuroanatomy of emotion: a meta-analysis of emotion activation studies in PET and fMRI. Neuroimage 16: 331-348.

9. Phillips ML, Drevets WC, Rauch SL, Lane R (2003) Neurobiology of emotion perception I: The neural basis of normal emotion perception. Biol Psychiat 54: 504-514.

10. Morris JS, Öhman A, Dolan RJ (1998) Conscious and unconscious emotional learning in the human amygdala. Nature 393: 467-470.

11. Sprengelmeyer R (2007) The neurology of disgust. Brain 130: 1715-1717.

12. Grainger SA, Henry JD, Phillips LH, Vanman EJ, Allen R (2015) Age Deficits in Facial Affect Recognition: The Influence of Dynamic Cues. The Journals of Gerontology Series B: Psychological Sciences and Social Sciences gbv100.

13. Ruffman T, Henry JD, Livingstone V, Phillips LH (2008) A meta-analytic review of emotion recognition and aging: Implications for neuropsychological models of aging. Neuroscience \& Biobehavioral Reviews 32: 863-881.

14. Wong B, Cronin-Golomb A, Neargarder S (2005) Patterns of visual scanning as predictors of emotion identification in normal aging. Neuropsychology 19: 739 .

15. Suzuki A, Hoshino T, Shigemasu K, Kawamura M (2007) Decline or improvement?: Age-related differences in facial expression recognition. Biol Psychol 74: 75-84.

16. Bartzokis G, Beckson M, Lu PH, Nuechterlein KH, Edwards N, et al (2001) Age-related changes in frontal and temporal lobe volumes in men: a magnetic resonance imaging study. Arch Gen Psychiat 58: 461-465.

17. Raz N, Lindenberger U, Rodrigue KM, Kennedy KM, Head D, et al. (2005) Regional brain changes in aging healthy adults: general trends, individual differences and modifiers. Cereb Cortex 15: 1676-1689.
18. Allen CT, Machleit KA, Kleine SS, Notani AS (2005) A place for emotion in attitude models. J Bus Res 58: 494-499.

19. Grieve SM, Clark CR, Williams LM, Peduto AJ, Gordon E (2005) Preservation of limbic and paralimbic structures in aging. Hum Brain Mapp 25: 391-401.

20. Shin LM, Wright CI, Cannistraro PA, Wedig MM, McMullin K, et al. (2005) A functional magnetic resonance imaging study of amygdala and medial prefrontal cortex responses to overtly presented fearful faces in posttraumatic stress disorder. Arch Gen Psychiat 62: 273-281.

21. Zimmerman ME, Brickman AM, Paul RH, Grieve SM, Tate DF, et al. (2006) The relationship between frontal gray matter volume and cognition varies across the healthy adult lifespan. The AM J Ger Psy 14: 823-833.

22. Raz N (2000) Aging of the brain and its impact on cognitive performance: Integration of structural and functional findings.

23. West $\mathrm{R}$ (2000) In defense of the frontal lobe hypothesis of cognitive aging. J Int Neuropsych Soc 6: 727-729.

24. Phillips LH, Henry JD (2005) An evaluation of the frontal lobe theory of cognitive aging. Measuring the mind: Speed, control and age 191-216.

25. Charles ST, Mather M, Carstensen LL (2003) Aging and emotional memory: the forgettable nature of negative images for older adults. J Exp Psyc Gen 132: 310.

26. Mather M, Carstensen LL (2003) Aging and attentional biases for emotional faces. Psychological Science 14: 409-415.

27. Sullivan S, Ruffman T, Hutton SB (2007) Age differences in emotion recognition skills and the visual scanning of emotion faces. The J Gerontology Series B: Psych Sci Soc Sci 62: P53-P60.

28. Williams LM, Brown KJ, Palmer D, Liddell BJ, Kemp AH, et al. (2006) The mellow years?: neural basis of improving emotional stability over age. The J Neurosci 26: 6422-6430. 